\title{
Copeptin as a Biomarker of Atherosclerosis in Type 1 Diabetic Patients
}

\author{
Soha M. Abd El Dayem ${ }^{1^{\star}}$, Ahmed A. Battah ${ }^{2}$, Abo El Magd El Bohy ${ }^{3}$, Rasha Nazih Yousef ${ }^{4}$, Ahmed Talaat $^{1}$ \\ ${ }^{1}$ Pediatrics Department, National Research Centre, Cairo, Egypt; ${ }^{2}$ Critical Care Department, Cairo University, Cairo, Egypt; \\ ${ }^{3}$ Radiology Department, Cairo University, Cairo, Egypt; ${ }^{4}$ Clinical Pathology Department, National Research Centre, Cairo, \\ Egypt
}

\begin{abstract}
Citation: El Dayem SMA, Battah AA, El Bohy AEM, Yousef RN, Talaat A. Copeptin as a Biomarker of Atherosclerosis in Type 1 Diabetic Patients. Open Access https://doi.org/10.3889/oamjms.2019.643

Keywords: Copeptin; CIMT; Type 1 diabetes

*Correspondence: Soha M. Abd El Dayem. Pediatric Department, National Research Centre, Cairo, Egypt. Email. S_eldayen@yahoo.com

Received: 07-Oct-2019; Revised: 06-Nov-2019; Accepted: 07-Nov-2019; Online first: 13-Dec-2020

Copyright: $\odot 2019$ Soha M. Abd El Dayem, Ahmed A. Battah, Abo El Magd El Bohy, Rasha Nazih Youse Ahmed Talaat. This is an open-access article distributed under the terms of the Creative Commons AttributionNonConmercial 4.0 International License (CCBY-NC 4.0) Funding: This research did not receive any financial support

Competing Interests: The authors have declared that no competing interests exis
\end{abstract}

\begin{abstract}
AIM: To evaluate copeptin as an early marker of atherosclerosis in adolescent type 1 diabetics.

METHODS: Sixty-two type 1 diabetic patients and 50 healthy volunteers were enrolled in the study. Serum copeptin, glycosylated haemoglobin $(\mathrm{HbA1c})$, lipid profile, oxidised low-density lipoprotein (OxLDL), urinary albumin/creatinine ratio, carotid intimal medial thickness (cIMT), aortic intimal medial thickness (alMT) and resistivity index were assessed for all participants in the study.

RESULTS: HbA1c, albumin/creatinine ratio, lipid profile, OxIDL, copeptin, cIMT and alMT were significantly higher in diabetic patients. Copeptin was higher in patients with positive CIMT and alMT. Copeptin correlated with cIMT and aIMT. Stepwise multiple regression analysis found that copeptin correlated with alMT. ROC curve showed that copeptin had $100 \%$ specificity with alMT and CIMT and 95.2 and 60,7 sensitivity with alMT and cIMT respectively.

CONCLUSION: Copeptin can be used as a marker for early detection of atherosclerosis of type 1 diabetic patients.
\end{abstract}

\section{Introduction}

Diabetic nephropathy (DN) and cardiac complication being considered the most important factor for morbidity and mortality in type 1 diabetes (T1D) [1], [2]. Early detection of the coronary artery plaque by using Coronary artery calcification (CAC) is an indication of endpoint coronary artery disease (CAD) [2].

As Arginine vasopressin (AVP) is small in size and had a short half-life, it can not be easily measured [3]. AVP is essential for renal and cardiovascular function as it regulates the volume status. Although Copeptin and AVP are derived from the same precursor molecule, copeptin is a more stable peptide and used for evaluation of fluid and osmosis status in various diseases [3], [4].

Type 1 diabetic patients had higher AVP and exaggerated response to AVP concentrations [5], [6], which stimulate $\mathrm{V} 1 \mathrm{a}$ receptors leading to diabetic cardiovascular complications. Although the relationship between copeptin, CAD and DN have been studied in adults with type 2 diabetes (T2D) [7], [8], yet from our knowledge, very minimal studies were done on type 1 diabetic patients.

We aimed to study the association between copeptin and atherosclerosis and diabetic nephropathy.

\section{Patients and Methods}

This cross-sectional study was done on 62 type of 1 diabetic patient and 50 healthy volunteers. The diabetic patients were selected from the endocrine clinic, Medical Center of Excellence, National Research Centre and the controls among 
healthy children attending the Medical centre of Excellence with their relatives. The ethical committee approval from National Research Centre, Registration number 19101 was taken. Also, written consent was received from diabetics or their parents and controls.

Diabetic patients (age $>14$ and $<19 \mathrm{yrs}$ ) and duration of diabetes more than 5 years were selected. On the other hand, people with diabetes with acute diabetic complications, CVD, taking metformin or multivitamins or Smokers were excluded from the study. Demographic data of diabetic patients was taken. General, cardiac, chest and neurological examination were done for all diabetics and controls. Blood pressure was assessed for all diabetics and controls. It was measured three times after 5-minute rest in the sitting position by using automatic manometer (Omron M4 Plus, Omron Health care Europe, Hoof drop, and Holland). The mean value of the second and the third measurement was calculated.

Weight, height, waist circumference (WC), and hip circumference $(\mathrm{HC})$ were assessed for diabetics and controls. Weight (by Seca Scale Standing Balance) and height (by Holtain Portable anthropometer, Holtain, Ltd, Crymmych, Wales, U.K) were measured. Body mass index, waist/hip ratio and waist/height ratio $(\mathrm{cm} / \mathrm{cm})$ were calculated [9], [10].

After $12 \mathrm{hr}$ fasting, venous blood was collected for assessment of lipid profile [11]. Lowdensity lipoprotein (LDL) cholesterol was calculated using the Friedewald equation. Triglycerides $(\mathrm{Tg})$ was measured in a Techno Con AutoAnalyzer II, Tarrytown, NY, USA.

The mean value of glycosylated haemoglobin $(\mathrm{HbA1c})$ of one year was recorded. Measurement of $\mathrm{HbA1c}$ every 3 was taken from files of patients.

Screening for microalbuminuria was assessed in fresh morning urine samples by measuring albumin/creatinine ratio. Microalbuminuria was measured 3 times (separated every 2 months), and it was considered positive if 2 from 3 samples were positive. If one sample was positive urine analysis was done to exclude urinary tract infection. Copeptin and OxLDL were measured by the ELISA method (quantitative sandwich enzyme-linked immunosorbent assay technique).

Assessment of Carotid intima-media thickness (cIMT) was done by using General Electric medical ultrasonographic machine model: Vivid 7 Pro, GE Vingmed ultrasound AS-NI90, Horton-Norway equipped with $7.5-10 \mathrm{MHz}$ linear-array transducer) [12].

\section{thickness (alMT)}

Measurement of the aortic intimal medial

The transducer $(7.5 \mathrm{MHz})$ was put in the upper abdomen for evaluation of abdominal aorta and aortic bifurcation. The aortic intima-media complex was assessed (10 MHz linear array transducer). For the assessment of alMT, the image was focused on the far wall (dorsal arterial wall of the most distal 15 $\mathrm{mm}$ of the abdominal aorta), and gain settings were used to optimise image quality [13]. The average of 3 measurements of each patient was taken for evaluation of alMT.

Renal colour duplex scan by Toshiba, Xario ultrasound machine (3-6 MHz transducer) was done in Rt and Lt renal arteries for measurement of the peak systolic velocities and excluded renal artery stenosis in all patients by assessment of different segments starting from their origins to renal hila. Right, and left resistivity indices in segmental, interlobar and arcuate arteries were also measured [14].

\section{Statistical Analysis}

Statistical Package for Social Science (SPSS) program version 20.0 (Chicago, Illinois, USA) was used. T-test for quantitative variables was done. We evaluate the correlation between copeptin with demographics, laboratory data, anthropometric data, and image study of diabetic patients. Pearson's correlation, followed by stepwise multiple regression analysis, were also done. Receiver Operating Characteristic curve (ROC curve) was used for detecting sensitivity and specificity of copeptin with cIMT and alMT. Stepwise multiple regression analysis of copeptin about demographics, anthropometric data, laboratory data and image study in type 1 diabetic patients

\section{Results}

Glycosylated haemoglobin, albumin/ creatinine ratio, lipid profile OxLDL, copeptin, cIMT and aIMT were significantly higher in people with diabetes (Table 1).

Table 1: Comparison between demographics, laboratory data, anthropometric and image study of diabetic patients and controls

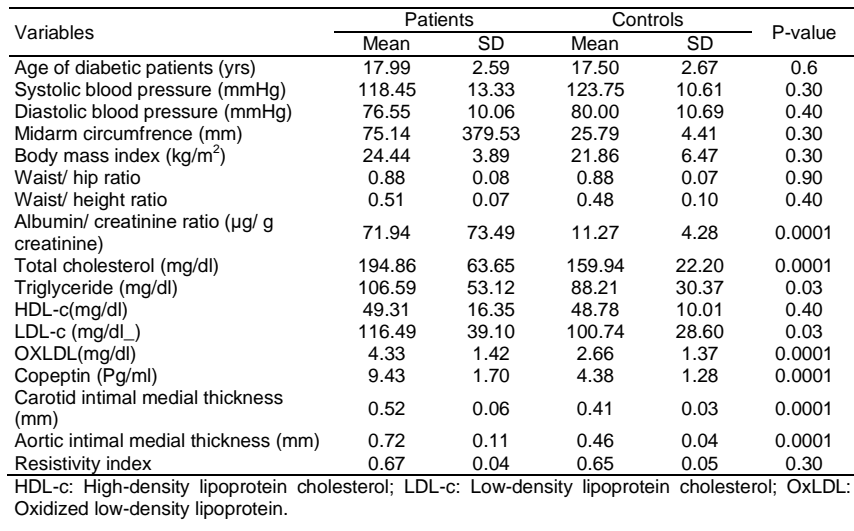


Copeptin was significantly higher in diabetic patients with positive alMT and cIMT (Table 2).

Table 2: Comparison between copeptin concerning aortic intimal medial thickness and carotid intimal medial thickness in type 1 diabetic patients

\begin{tabular}{cccccc}
\hline & \multicolumn{2}{c}{ Negative alMT } & \multicolumn{2}{c}{ Positive alMT } & \multirow{2}{*}{ P-value } \\
\cline { 2 - 5 } & Mean & SD & Mean & SD & \\
\cline { 2 - 5 } Copeptin (Pg/ml) & 6.65 & 0.49 & 9.54 & 1.65 & 0.02 \\
\cline { 2 - 5 } & $\begin{array}{c}\text { Negative } \\
\text { ClMT }\end{array}$ & $\begin{array}{c}\text { Positive } \\
\text { CIMT }\end{array}$ & $\begin{array}{c}\text { Negative } \\
\text { clMT }\end{array}$ & $\begin{array}{c}\text { Positive } \\
\text { cIMT }\end{array}$ & \multirow{2}{*}{0.0001} \\
& Mean & SD & Mean & SD & \\
\cline { 2 - 5 } & 8.08 & 0.98 & 8.08 & 0.98 & \\
\hline
\end{tabular}

aIMT: Aortic intimal medial thickness; cIMT: carotid intimal medial thickness.

Copeptin had a positive correlation with age of diabetic patients, cIMT and alMT (Table 3).

Table 3: Correlation between copeptin with demographics, laboratory data, anthropometric data and image study of diabetic patients

\begin{tabular}{|c|c|c|}
\hline \multirow{2}{*}{ Variables } & \multicolumn{2}{|c|}{ Copeptin } \\
\hline & $\mathrm{r}$ & P-value \\
\hline \multicolumn{3}{|l|}{ Demographic data } \\
\hline Age of diabetic patients (yrs) & 0.32 & 0.01 \\
\hline Duration of diabetes (yrs) & 0.11 & 0.39 \\
\hline Onset of disease (yrs) & 0.23 & 0.07 \\
\hline Insulin dose $(\mathrm{u} / \mathrm{kg})$ & 0.04 & 0.75 \\
\hline \multicolumn{3}{|l|}{ Blood pressure $(\mathrm{mmHg})$} \\
\hline Systolic blood pressure (mmHg) & 0.02 & 0.85 \\
\hline Diastolic blood pressure (mmHg) & 0.06 & 0.65 \\
\hline \multicolumn{3}{|l|}{ Anthropometric data } \\
\hline Midarm circumference $(\mathrm{mm})$ & 0.18 & 0.17 \\
\hline Body mass index $(\mathrm{kg} / \mathrm{m} 2)$ & 0.12 & 0.37 \\
\hline Waist/ hip ratio & 0.13 & 0.32 \\
\hline Waist/height ratio & 0.17 & 0.18 \\
\hline \multicolumn{3}{|l|}{ Laboratory data } \\
\hline $\mathrm{HbA1c}(\%)$ & 0.02 & 0.87 \\
\hline $\begin{array}{l}\text { Albumin/ creatinine ratio }(\mu \mathrm{g} / \mathrm{g} \\
\text { creatinine) }\end{array}$ & 0.05 & 0.78 \\
\hline Total cholesterol (mg/dl) & 0.10 & 0.47 \\
\hline Triglyceride $(\mathrm{mg} / \mathrm{dl})$ & 0.14 & 0.30 \\
\hline HDL-c $(\mathrm{mg} / \mathrm{dl})$ & 0.08 & 0.57 \\
\hline LDL-c $(\mathrm{mg} / \mathrm{dl})$ & 0.03 & 0.82 \\
\hline OxLDL (mg/dl) & 0.06 & 0.62 \\
\hline \multicolumn{3}{|l|}{ Image study } \\
\hline $\begin{array}{l}\text { carotid intimal medial } \\
\text { thickness }(\mathrm{mm})\end{array}$ & 0.40 & 0.0001 \\
\hline $\begin{array}{l}\text { Aortic intimal medial thickness } \\
(\mathrm{mm})\end{array}$ & 0.86 & 0.0001 \\
\hline Resistivity index & 0.11 & 0.40 \\
\hline
\end{tabular}

Low-density lipoprotein cholesterol; OxLDL: Oxidized low-density lipoprotein.

Stepwise multiple regression analysis of copeptin concerning demographic, anthropometric data, laboratory data and image study in type 1 diabetic patients were shown in Table 4.

Table 4: Stepwise multiple regression analysis of copeptin about demographics, anthropometric data, laboratory data and image study in type 1 diabetic patients

\begin{tabular}{lccccc}
\hline & \multicolumn{2}{c}{ Unstandardized coefficent } & \multicolumn{2}{c}{ Standardized coefficent } & \multirow{2}{*}{ P-value } \\
\cline { 2 - 5 } & $\mathrm{B}$ & $\mathrm{SE}$ & $\mathrm{B}$ & $\mathrm{t}$ & \\
\hline (Constant) & 2.14 & 1.59 & & 1.35 & 0.19 \\
alMT (mm) & 10.23 & 2.06 & 0.76 & 4.97 & 0.0001 \\
\hline
\end{tabular}

Dependent variables are copeptin; alMT: aortic intimal medial thickness.

ROC curve of copeptin for detection of atherosclerosis in relation to carotid intimal medial thickness and aortic intimal medial thickness in type 1 diabetic (Table 5).
Table 5: ROC curve of copeptin for detection of atherosclerosis concerning carotid intimal medial thickness and aortic intimal medial thickness in type 1 diabetic patients

\begin{tabular}{lcccccc}
\hline Variables & Cut off & AUC & SE & $95 \%$ C.I & Sensitivity & Specificity \\
\hline CIMT & $>9$ & 0.8 & 0.07 & $0.7-0.9$ & 60.7 & 100 \\
alMT & $>7$ & 1.0 & 0.02 & $0.9-1.0$ & 95.2 & 100 \\
\hline \multicolumn{2}{l}{ ROC: Receiver } & operating & characteristic curve; & alMT: Aortic & intimal medial thickness; cIMT:
\end{tabular}

ROC: Receiver operating characteristic curve; alMT: Aortic intimal medial thickness; cIMT: Carotid intimal medial thickness; AUC: Area under the curve; SE: Standard error; $\mathrm{Cl}$ : Confidence interval.

\section{Discussion}

In our study, adolescent type 1 diabetic patients had higher $\mathrm{HbA} 1 \mathrm{c}$, microalbuminuria, dyslipidemia and higher aIMT and cIMT. aIMT was found to be higher than cIMT in diabetic patients. This result is comparable with previous studies [15], [16]. Järvisalo et al., [17] revealed that young type 1 diabetic patients had an increased incidence of subclinical atherosclerosis. McGill et al., [12] found that intima of the abdominal aorta is affected before intima of the carotid artery and alMT is an early diagnosis of preclinical atherosclerosis in children [18].

In the current study, copeptin was higher in adolescent type 1 diabetics and patients with higher cIMT and aIMT. Stepwise multiple regression analysis revealed that copeptin had a significant correlation with aIMT. Our results are comparable with the result of [19]. Copeptin had a strong relationship with atherosclerosis and diabetic kidney disease in adult's type 1 diabetic patient [19].

In the present study, copeptin had no significant correlation with albumin/creatinine ratio. As Copeptin and AVP are secreted from neurohypophysis, their level increase in many medical conditions in type 2 diabetic patients such as acute myocardial infarction [20], cardiovascular mortality [3] and diabetic kidney disease.

Vasopressin may lead to an increase in blood pressure (systemic and glomerular) as it leads to an increase in vasoconstriction of blood vessels, enhancing gluconeogenesis, glucagon release and leads to fat accumulation. Vasopressin aggravates kidney disease in animals and leads to an increase in proteinuria in humans [2].

Bjornstad et al., [19], revealed that copeptin is high in adult type 1 diabetic patients and is related to albuminuria, impaired glomerular filtration rate (GFR) and increase in coronary calcium calcification. Increase copeptin level is associated with cardiorenal complications irrespective to the control of blood glucose, lipid profile and blood pressure. Also, Schiel et al., [21] reported that copeptin might be considered as a marker of renal function in children and adolescents with type 1 diabetes mellitus. Moreover, the concentration of copeptin may also be related to stress, behavioural and lifestyle factors as well as 
inflammatory activity and the lipid profile.

In the current study, ROC curve of copeptin showed that the cut off level of copeptin for detection of alMT was > 7 with specificity and sensitivity $100 \%$ and $95.2 \%$ respectively and for cIMT cut off was $>9$ and specificity and sensitivity $100 \%$ and $60.7 \%$. Copeptin has better sensitivity and specificity with aIMT, which is early affected before cIMT and can be used as early detection of atherosclerosis.

In conclusion, copeptin is high in adolescent type 1 diabetic patients irrespective of control of blood glucose, dyslipidemia and hypertension. It can be used for early detection of atherosclerosis. Copeptin has no relation to diabetic nephropathy. AVP (Vapans) can be given to adolescent type 1 diabetic patients with cardiorenal complications. A follow-up study and increase number of patients is recommended to detect if copeptin is a cause of occurrence of diabetic atherosclerosis.

\section{References}

1. De Ferranti SD, De Boer IH, Fonseca V, Fox CS, Golden SH, Lavie CJ, Magge SN, Marx N, McGuire DK, Orchard TJ, Zinman B. Type 1 diabetes mellitus and cardiovascular disease: a scientific statement from the American Heart Association and American Diabetes Association. Circulation. 2014; 130(13):1110-30. https://doi.org/10.1161/CIR.0000000000000034 PMid:25114208

2. Snell-Bergeon JK, Maahs DM. Diabetes: Elevated risk of mortality in type 1 diabetes mellitus. Nature reviews Endocrinology. 2015; 11:136-138. https://doi.org/10.1038/nrendo.2014.245 PMid:25583696

3. Bardoux P, Martin H, Ahloulay M, et al. Vasopressin contributes to hyperfiltration, albuminuria, and renal hypertrophy in diabetes mellitus: study in vasopressin-deficient Brattleboro rats. Proceedings of the National Academy of Sciences of the United States of America. 1999; 96:10397-10402. https://doi.org/10.1073/pnas.96.18.10397 PMid:10468619 PMCid:PMC17899

4. Yan J, Navaneethan SD. Copeptin and Decline in Kidney Function. Am J Nephrol. 2016; 44:19-21. https://doi.org/10.1159/000447369 PMid:27348731 PMCid:PMC5408578

5. Zerbe RL, Vinicor F, Robertson GL. Plasma vasopressin in uncontrolled diabetes mellitus. Diabetes. 1979; 28:503-508. https://doi.org/10.2337/diab.28.5.503 PMid:108167

6. Coiro V, Capretti L, Speroni G, et al. Abnormal argininevasopressin responses to metoclopramide and insulin-induced hypoglycemia in type I diabetes mellitus. Hormone research. 1990; 33:227-232. https://doi.org/10.1159/000181521 PMid:2289781

7. Fenske W, Wanner C, Allolio B, et al. Copeptin levels associate with cardiovascular events in patients with ESRD and type 2 diabetes mellitus. J Am Soc Nephrol. 2011; 22:782-790. https://doi.org/10.1681/ASN.2010070691 PMid:21415158 PMCid:PMC3065233

8. Riphagen IJ, Boertien WE, Alkhalaf A, Kleefstra N, Gansevoort RT, Groenier KH, Van Hateren KJ, Struck J, Navis G, Bilo HJ, Bakker SJ. Copeptin, a surrogate marker for arginine vasopressin, is associated with cardiovascular and all-cause mortality in patients with type 2 diabetes (ZODIAC-31). Diabetes Care. 2013 36(10):3201-7. https://doi.org/10.2337/dc12-2165 PMid:23757433 PMCid:PMC3781508

9. Cameron $\mathrm{N}$. The methods of auxological anthropology. In: Falkner F, Tanner JM, editors. Human growth 3 Methodology. New York: Plenum Press, 1986:3-46. https://doi.org/10.1007/978-14615-7198-8 1 PMid:3956717

10. Tanner JM, Hiernaux J, Jarman S. Growth and physical studies. In: Weiner JS, Lourie JA, editors. Human biology: a guide to field methods. Oxford: Blackwell Scientific Publ., 1969:3-41.

11. Friedewald W. T., Levy R. I. and Fredrickson D. S. Estimation of the concentration of low-density lipoprotein cholesterol in plasma, without use of preparative ultracentrifuge. Clin Chem. 1972; 18(6):499-02.

12. Singh TP, Groehn H, Kazmers A. Vascular function and carotid intimal-medial thickness in children with insulin-dependent diabetes mellitus. J Am Coll Cardiol. 2003; 41:661-665. https://doi.org/10.1016/S0735-1097(02)02894-2

13. McGill HC, McMahan CA, Herderick EE, et al. Effects of coronary heart disease risk factors on atherosclerosis of selected regions of the aorta and right coronary artery: PDAY research group: Pathobiological Determinants of Atherosclerosis in Youth. Arterioscler Thromb Vasc Biol. 2000; 20: 836-845 https://doi.org/10.1161/01.ATV.20.3.836 PMid:10712411

14. Saif A, Soliman NA, Abdel-Hameed A. Early evaluation of renal hemodynamic alterations in type I diabetes mellitus with duplex ultrasound. Saudi J Kidney Dis Transpl 2010; 21:295-9.

15. Soha M. Abd El Dayem, Ahmed A. Battah, Abo El Magd EI Bohy. Assessment of Increase in Aortic and Carotid Intimal Medial Thickness in Type 1 Diabetic Patients. Open Access Macedonian Journal of Medical Sciences. 2016; 4(4):630-635.

https://doi.org/10.3889/oamims.2016.118 PMid:28028403 PMCid:PMC5175511

16. McGill Jr. HC, McMahan CA, Gidding SS. Preventing hear disease in the 21st century: implications of the Pathobiological Determinants of Atherosclerosis in Youth (PDAY) study Circulation. 2008; 117:1216-1227.

https://doi.org/10.1161/CIRCULATIONAHA.107.717033 PMid:18316498

17. Järvisalo MJ, Jartti L, Näntö-Salonen K, Irjala K, Rönnemaa T, Hartiala JJ, Celermajer DS, Raitakari OT. Increased aortic intimamedia thickness: a marker of preclinical atherosclerosis in high-risk children. Circulation. 2001; 104:2943-2947.

https://doi.org/10.1161/hc4901.100522 PMid:11739310

18. Soha M. Abd El Dayem, Abo El Magd El Bohy and Ahmed A Battah. Carotid intimal medial thickness and its relation to endothelial dysfunction and echocardiographic changes in adolescents with type 1 diabetes. J Pediatr Endocrinol Metab. 2015; 28(9-10):1029-1037. https://doi.org/10.1515/jpem-2014-0355

19. Bjornstad P, Maahs DM, Jensen T, Lanaspa MA, Johnson RJ, Rewers M, and Snell-Bergeon JK. Elevated copeptin is associated with atherosclerosis and diabetic kidney disease in adults with type 1 diabetes. J Diabetes Complications. 2016; 30(6):1093-1096. https://doi.org/10.1016/j.jdiacomp.2016.04.012 PMid:27141815 PMCid:PMC4949105

20. Reichlin T, Hochholzer W, Bassetti S, et al. Early diagnosis of myocardial infarction with sensitive cardiac troponin assays. N Engl J Med. 2009; 361:858-867. https://doi.org/10.1056/NEJMoa0900428 PMid:19710484

21. Schiel R, Perenthaler TJ, Steveling A, Stein G. Plasma copeptin in children and adolescents with type 1 diabetes mellitus in comparison to healthy controls. Diabetes research and clinical practice. 2016; 118:156-61.

https://doi.org/10.1016/i.diabres.2016.06.019 PMid:27371782 